Original Article

\title{
Tegumental changes induced in adult $S$. mansoni by limonin: animal experimental and electron microscopic studies
}

\author{
Gehan A Rashed ${ }^{1}$, Asmaa A Elkholy ${ }^{1}$, Dalia I Hemdan² \\ ${ }^{1}$ Departments of Parasitology and ${ }^{2}$ Pharmacognosy, ${ }^{1}$ Faculty of Medicine, Benha University, \\ and ${ }^{2}$ Faculty of Pharmacy, Zagazig University, Egypt
}

\begin{abstract}
Background: Praziquantel (PZQ) is the drug of choice recommended by the World Health Organization for the treatment and control of human schistosomiasis. The fact that schistosomes are developing resistance to PZQ indicates the urgent need for new effective treatment compounds. Herbal medicinal products, either as pure compounds or as standardized plant extracts, have been employed successfully for the development of new drugs. Limonin which is a citrus fruit compound has been reported to possess a wide range of biological activities.

Aim of the work: To investigate in vitro the therapeutic efficacy of limonin as an alternative anti-schistosomal compound. Material and Methods: The in vitro assay was carried out on adult Schistosoma mansoni worms (Egyptian strain) using four concentrations of limonin in RPMI-1640 culture medium (15.6, 31.2, 62.5, $125.0 \mu \mathrm{g} / \mathrm{mL})$. Schistosomes recovered from all groups were processed for ultrastructural investigation by scanning electron microscopy.

Results: Limonin at a concentration of $125.0 \mu \mathrm{g} / \mathrm{mL}$ reduced the worm motor activity and caused death of all male schistosomes, which were more susceptible. The product had a concentration-dependent response effect within a smaller period of exposure. Female worms showed less prominent effects (death) at higher tested concentrations associated with reduction in the motor activity. This effect decreased with reduction of concentration . On the ultrastructural level, limonin at higher concentrations induced massive tegument destruction exposing the sub-tegument tissues.

Conclusion: Obtained data confirm that limonin is effective against adult S. mansoni in vitro and presents a potential for the development of a candidate anti-parasitic agent.
\end{abstract}

Key Words: in vitro, limonin, orange dried seeds, scanning electron microscopy, S. mansoni.

Received: 11 July 2017, Accepted: 8 February, 2018.

Corresponding Author: Gehan A Rashed, Tel. : +20-12-2289-0144 , E-mail: gehan.abdelrahman@yahoo.com.

ISSN: 1687-7942, Vol. 11, No. 1, April 2018.

\section{INTRODUCTION}

Schistosomiasis is listed as one of the neglected tropical diseases. It affects over 250 million people worldwide and presents a major public health problem in 78 tropical and subtropical countries. The majority (up to $90 \%$ ) of the cases are located mainly in sub-Saharan Africa ${ }^{[1,2]}$. Praziquantel is the major chemotherapeutic agent for treatment of schistosomiasis as well as other helminthesiasis ${ }^{[3-5]}$. In view of the growing resistance to this therapy, attempts are made to explore other new anti-schistosomal options ${ }^{[6]}$. There is now a promising tendency for the use of natural compounds derived from plant extracts as drugs against Schistosoma spp., being safe and with less medical side effects $^{[7-9]}$. A review article was published in 2013 and in its first part, the reviewer focused on all drugs recommended from WHO for treatment of schistosomiasis during the last 6 decades, as well as all herbal medicines tested in several studies in comparison with PZQ. It also dealt with PZQ resistance in several African countries and its mechanism(s), mentioning methods for measurement of susceptibility or resistance of Schistosoma spp. to PZQ. The second part of the review discussed informatics and new technology in
Schistosoma spp. genomics and proteomics that allowed scientists to develop new anti-schistosomal drugs. Finally, several studies that utilized the fast progress in molecular technology conducted during the period from 2000-2012 were summarized ${ }^{[10]}$.

Citrus fruits are regarded for their content of certain compounds (limonoids) with extremely bitter taste mainly accumulated in seeds. The term limonoids was derived from limonin, the first tetranortriterpenoid obtained from citrus bitter principles ${ }^{[11]}$. Limonin is a highly oxygenated triterpenoid dilactone, which is particularly abundant in the seeds of citrus fruits as the Rutaceae and Meliaceae families ${ }^{[12]}$. Limonoids have recently been found to possess multiple in vitro and in vivo biological functions ${ }^{[13]}$. Other biological activities include insecticidal, insect antifeeding and growth regulating activities in insects, as well as being antiviral, anticancer, cholesterol-lowering and antioxidant $^{[14-19]}$. Limonoids as limonin and nomilin have been found to induce increased activity of the detoxifying enzyme glutathione-S-transferase. The increased enzyme activity was found to correlate with the ability of these compounds to inhibit chemically induced carcinogenesis 
in laboratory animals ${ }^{[20,21]}$. Toxicological studies reported possibility of hepatotoxicity due to the use of herbal medicine. Another recent study in 2014 on rats showed that limonin proved to have hepatoprotective effects against liver toxicity. This occurs either directly through antioxidant effects, or indirectly through inhibition of TNF- $\alpha$ production and subsequent suppression of eosinophils infiltration in D-galactosamine-induced liver injury ${ }^{[22]}$.

Several researchers studied the alterations in the surface topography of schistosomes by scanning electron microscopy (SEM). This was employed for the evaluation of several drugs/compounds, since the tegument of schistosomes is an important target for such drugs ${ }^{[23-25]}$.

In spite of this wide range of therapeutic activities, little information is available about the anti-helminthic effects of limonoids. Hamed and Hetta reported that treatment with C. reticulata (Mirazid) improved succinate dehydrogenase (SDH), lactate dehydrogenase (LDH) and its isoenzymes, glucose-6-phosphatase (G-6-Pase), acid phosphatase (AP), 5'- nucleotidase, and liver function enzymes activities in $S$. mansoni infected mice with a noticeable reduction in ova count and worm burden ${ }^{[26]}$. Co-administration of grapefruit juice with artemether achieved complete protection of the host from damage induced by schistosomal infection ${ }^{[27]}$. Therefore, the present study investigated, whether limonin, which is the most abundant limonoid in citrus fruit, has an anti-schistosomal activity against mature $S$. mansoni in vitro.

\section{MATERIAL AND METHODS}

The present experimental descriptive study was carried out at Schistosome Biological Supply Center (SBSC), Theodor Bilharz Research Institute (TBRI), Giza, Egypt during the period from December 2015 to March 2016.

Plant material and extraction procedure: Bitter sweet orange (Citrus aurantium var. bigaradia Hook f., Citrus bigaradia Risso and Poit, C. bigaradia Loisel; Rutaceae) was used in this study. The selection of this plant was made on the basis of information gathered about its use in traditional medicine. Dried seeds were obtained from the Research Center of El-Qanater El-Khireya, Qalubyia, Egypt. The seeds were collected from ripe fruits, cleaned, dried in the shade and ground into powdered form.

Preparation of the plant extract: Limonin with molecular formula: C26H30O8 (Figure 1) was prepared in Department of Pharmacognosy, Faculty of Pharmacy, Zagazig University according to the method described by Mahmoud et al. ${ }^{[22]}$. A voucher specimen (P-80, 81) was deposited in the herbarium of the Faculty of Pharmacy, Zagazig University. Briefly, the dried powder was defatted with light petroleum and extracted with methanol. This

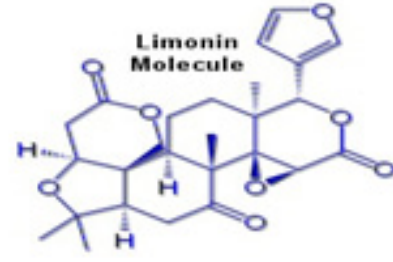

Fig. 1: Chemical structure of limonin (7,16-Dioxo-7,16dideoxylimondiol)

concentrated methanolic extract was then suspended in water and extracted with $\mathrm{CH} 2 \mathrm{Cl} 2$. The solvent was evaporated under vacuum to give a brownish yellow oily residue.

Isolation of the compounds: The dry mixed initial zone of the dichloromethane fraction was chromatographed over a silica gel column, eluted using cyclohexane then the polarity was increased gradually using ethyl acetate followed by methanol. Fractions $250 \mathrm{~mL}$ each were collected, concentrated under vacuum and monitored by thin layer chromatography (TLC) using solvent systems ${ }^{[28]}$.

Spectral analysis using liquid chromatography electrospray mass spectrometry (LC-ESI/MS) for limonoids: Chromatographic separation was carried out using RP C-18 LiChro CART (Merck- Darmstadt) column to identify the minor limonoids in the dichloromethane fraction. The purity of limonin used in the present study and tested using high performance liquid chromatography (HPLC) was $>97 \%$. Spectral data for limonin was as described by Hamdan et al. ${ }^{[28]}$ while, the procedure used for LC-ESI/MS of limonoid was as illustrated by Mahmoud et $a l .{ }^{[22]}$.

As a benchmark, PZQ was purchased from Sigma Aldrich. Both limonin and PZQ were dissolved in $0.5 \%$ dimethyl sulfoxide (DMSO, Sigma-Aldrich) immediately before use.

Animals and parasites: Five adult male Syrian golden hamsters (Mesocricetus auratus), 100-120 g each, were purchased from SBSC, TBRI, Giza, Egypt. They were maintained under environmentally-controlled conditions (temperature $25^{\circ} \mathrm{C}$; humidity $70 \% ; 12 \mathrm{~h}$ light and $12 \mathrm{~h}$ dark cycle) and acclimatized for one week before infection. Three hundred S. mansoni cercariae (Egyptian strain) were used to infect each hamster by abdominal skin exposure according to the infection protocol of SBSC, TBRI.

Experimental design: The in vitro schistosomicidal assay was conducted according to the method described by Yousef et $a l .{ }^{[29]}$ and the modification carried out by El Beshbishi et al. ${ }^{[30]}$. Briefly, S. mansoni, mature parasites were recovered by perfusion from portal and mesenteric 
veins of $8 \mathrm{w}$ infected hamsters. Freshly recovered viable adult schistosomes were washed three times in PBS then washed again in RPMI 1640 culture medium then placed in fresh medium and stored in an incubator chamber at $37^{\circ} \mathrm{C}$. Adult worms were incubated in a 24 -well culture plate (TPP, St. Louis, MO, USA), placing 3-6 pair of worms in each well, containing the RPMI 1640 medium at $37^{\circ} \mathrm{C}$ in a 5\% CO2 atmosphere. Limonin was dissolved in DMSO $0.5 \%$ and tested at concentrations of 15.6 to $125.0 \mu \mathrm{g} / \mathrm{ml}$ $(15.6,31.2,62.5,125.0 \mu \mathrm{g} / \mathrm{ml})$ in culture plates with a final volume of $2 \mathrm{ml}$. The control worms were assayed in RPMI 1640 medium alone, and in RPMI 1640 medium containing $0.5 \%$ DMSO without drugs as negative controls groups and $10.0 \mu \mathrm{g} / \mathrm{ml}$ PZQ (reference drug) as positive control group. Each test was performed in duplicate and repeated at least two times. The parasites were kept for $96 \mathrm{~h}$ and monitored using an inverted microscope every $24 \mathrm{~h}$. The effect of the drug was assessed with emphasis on changes in worm viability, worm motor activity and alteration in the tegument as previously described ${ }^{[31]}$. Parasites showing no body contractions for at least 1 to 2 min of observation were considered dead (i.e. no worm movement after 1-2 min without motor activity $)^{[32-33]}$. In addition, worms were also examined using scanning electron microscopy.

SEM study: To observe the morphological changes in the tegument of the adult parasites, schistosomes were monitored using SEM following standard procedure as described by Hassan et al.$^{[34]}$. Briefly, samples of $S$. mansoni adult worms understudy were, washed twice in PBS for $10 \mathrm{~min}$ then fixed in 3\% glutaraldehyde buffer solution over night at $4^{\circ} \mathrm{C}$. Worms were then washed of any trace of fixative by keeping them over night at $4^{\circ} \mathrm{C}$ in PBS, then post-fixed in $1 \%$ Osmium tetroxide $(\mathrm{OsO} 4)$ for one hour. Samples were then washed and dehydrated in ascending grades of ethyl alcohol $(30 \%, 40 \%, 50 \%)$ for 15 min each. Worms were then kept in $70 \%$ ethyl alcohol until examination. Before examination, they were washed twice for $30 \mathrm{~min}$ in $80 \%$ and $90 \%$ ethyl alcohol respectively. The last wash was for one hour in $95 \%$ ethyl alcohol, after which worms were mounted on stainless steel holders and put in a drier for about $30 \mathrm{~min}$ and then subjected to sputter coat of gold. Different parts of worms were examined using Joel JEM-1200 scanning electron microscope, fitted with a camera. Areas in the worms that showed specific changes were examined and photographed mainly suckers and tegumental tubercles ${ }^{[35]}$.

Statistical analysis: Data were analyzed using statistical program SPSS version 20 (USA). Quantitative data was represented by using mean and standard deviation, and analyzed using correlation coefficient ( $\mathrm{r}$ ) and ANOVA test ( $F$ value). The first was used to measure the closeness of the association between two continuous variables. Linear regression: is the standard method for determining whether 2 variables are correlated; i.e. $\mathrm{X}=\mathrm{Y}, 2 \mathrm{X}=2 \mathrm{Y}$, so $\mathrm{X}$ and $\mathrm{Y}$ are correlated. Regression coefficient $=$ coefficient of correlation $=\mathrm{r}$ which indicates the degree of correlation between $\mathrm{X}$ and $\mathrm{Y}$, while value of 1 indicates perfect correlation and value of 0 indicates no correlation at all. ANOVA test was used to compare mean of more than two groups of quantitative data with post hoc multiple comparison (LSD). Significance level was considered if $P$ $<0.05$.

Ethical considerations: The present study was approved by the Ethical Committee of Faculty of Medicine, Benha University, Egypt. The experimental animal studies were conducted in accordance with the ethical guidelines approved by the Ethical Committee of the Federal Legislation and National Institutes of Health Guidelines in the USA and were approved by the Medical Ethical Committee of TBRI. All the animals were handled in strict accordance with good animal practice as defined by the "Animals Use Ethics Committee" of Faculty of Medicine, Benha University, Egypt. The maintenance and care during experimentation of animals was compliant with international guidelines for the human use of laboratory animals.

\section{RESULTS}

The results of the current in vitro study with adult S. mansoni worms exposed to limonin at concentrations of $15.6,31.2,62.5$ and $125.0 \mu \mathrm{g} / \mathrm{ml}$ and control groups are summarized in tables $(1,2)$, and figure (2). At 125.0 $\mu \mathrm{g} / \mathrm{ml}$ concentration, limonin was lethal to $100 \%$ of male adult parasites after $72 \mathrm{~h}$ of in vitro exposure. With the same concentration and within the same time period, little mortality was observed in female worms, accompanied with significant reduction of motor activity. At concentrations less than $62.5 \mu \mathrm{g} / \mathrm{ml}$, reduction in the schistosome motility was the only observed finding. In the negative control groups (RPMI 1640 medium only and RPMI 1640 medium containing 0.5\% DMSO without limonin), no impact was observed on worm motor activity or survival. The schistosomes showed normal motor activity and had no observed mortality. In the $10.0 \mu \mathrm{g} /$ $\mathrm{ml}$ PZQ treated control group, there was complete loss of motor activity associated with death of all parasites within the first $24 \mathrm{~h}$ post incubation. The present study also showed significant correlation between increasing limonin concentration (from $15.6 \mu \mathrm{g} / \mathrm{ml}$ up to $125 \mu \mathrm{g} / \mathrm{ml}$ ) and both mortality of male worms and reduction in worms motor activity (Table 2). 
PARASITOLOGISTS UNITED JOURNAL

Table 1: Effect of different limonin concentrations on mature S. mansoni

\begin{tabular}{|c|c|c|c|c|c|}
\hline \multirow{2}{*}{ Group } & \multirow{2}{*}{$\begin{array}{l}\text { Incubation } \\
\text { Period (h) }\end{array}$} & \multicolumn{2}{|c|}{$\%$ of dead worms } & \multicolumn{2}{|c|}{$\%$ of motor activity reduction } \\
\hline & & Male & Female & Male & Female \\
\hline \multirow{4}{*}{$\begin{array}{l}\text { Control (-ve) } \\
\text { RPMI } 1640 \text { medium }\end{array}$} & $24 \mathrm{~h}$ & $0 \%$ & $0 \%$ & $0 \%$ & $0 \%$ \\
\hline & $48 \mathrm{~h}$ & $0 \%$ & $0 \%$ & $0 \%$ & $0 \%$ \\
\hline & $72 \mathrm{~h}$ & $0 \%$ & $0 \%$ & $0 \%$ & $0 \%$ \\
\hline & $96 \mathrm{~h}$ & $0 \%$ & $0 \%$ & $0 \%$ & $0 \%$ \\
\hline \multirow{4}{*}{$\begin{array}{l}\text { RPMI } 1640 \text { medium } \\
\text { containing } 0.5 \% \text { DMSO }\end{array}$} & $24 \mathrm{~h}$ & $0 \%$ & $0 \%$ & $0 \%$ & $0 \%$ \\
\hline & $48 \mathrm{~h}$ & $0 \%$ & $0 \%$ & $0 \%$ & $0 \%$ \\
\hline & $72 \mathrm{~h}$ & $0 \%$ & $0 \%$ & $0 \%$ & $0 \%$ \\
\hline & $96 \mathrm{~h}$ & $0 \%$ & $0 \%$ & $0 \%$ & $0 \%$ \\
\hline \multirow{4}{*}{$\begin{array}{l}\text { Control (+ve) } \\
(\text { PZQ } 10.0 \mu \mathrm{g} / \mathrm{ml})\end{array}$} & $24 \mathrm{~h}$ & $100 \%$ & $100 \%$ & $100 \%$ & $100 \%$ \\
\hline & $48 \mathrm{~h}$ & $100 \%$ & $100 \%$ & $100 \%$ & $100 \%$ \\
\hline & $72 \mathrm{~h}$ & $100 \%$ & $100 \%$ & $100 \%$ & $100 \%$ \\
\hline & $96 \mathrm{~h}$ & $100 \%$ & $100 \%$ & $100 \%$ & $100 \%$ \\
\hline \multirow{4}{*}{$\begin{array}{l}\text { Limonin } \\
125.0 \mu \mathrm{g} / \mathrm{ml}\end{array}$} & $24 \mathrm{~h}$ & $10 \%$ & $0 \%$ & $100 \%$ & $30 \%$ \\
\hline & $48 \mathrm{~h}$ & $60 \%$ & $30 \%$ & $100 \%$ & $60 \%$ \\
\hline & $72 \mathrm{~h}$ & $100 \%$ & $50 \%$ & $100 \%$ & $100 \%$ \\
\hline & $96 \mathrm{~h}$ & $100 \%$ & $70 \%$ & $100 \%$ & $100 \%$ \\
\hline \multirow{4}{*}{$\begin{array}{l}\text { Limonin } \\
62.5 \mu \mathrm{g} / \mathrm{ml}\end{array}$} & $24 \mathrm{~h}$ & $0 \%$ & $0 \%$ & $60 \%$ & $20 \%$ \\
\hline & $48 \mathrm{~h}$ & $33.3 \%$ & $10 \%$ & $100 \%$ & $50 \%$ \\
\hline & $72 \mathrm{~h}$ & $50 \%$ & $20 \%$ & $100 \%$ & $100 \%$ \\
\hline & $96 \mathrm{~h}$ & $70 \%$ & $40 \%$ & $100 \%$ & $100 \%$ \\
\hline \multirow{4}{*}{$\begin{array}{l}\text { Limonin } \\
31.2 \mu \mathrm{g} / \mathrm{ml}\end{array}$} & $24 \mathrm{~h}$ & $0 \%$ & $0 \%$ & $0 \%$ & $0 \%$ \\
\hline & $48 \mathrm{~h}$ & $0 \%$ & $0 \%$ & $0 \%$ & $0 \%$ \\
\hline & $72 \mathrm{~h}$ & $20 \%$ & $10 \%$ & $40 \%$ & $20 \%$ \\
\hline & $96 \mathrm{~h}$ & $40 \%$ & $20 \%$ & $100 \%$ & $50 \%$ \\
\hline \multirow{4}{*}{$\begin{array}{l}\text { Limonin } \\
15.6 \mu \mathrm{g} / \mathrm{ml}\end{array}$} & $24 \mathrm{~h}$ & $0 \%$ & $0 \%$ & $0 \%$ & $0 \%$ \\
\hline & $48 \mathrm{~h}$ & $0 \%$ & $0 \%$ & $0 \%$ & $0 \%$ \\
\hline & $72 \mathrm{~h}$ & $0 \%$ & $0 \%$ & $0 \%$ & $0 \%$ \\
\hline & $96 \mathrm{~h}$ & $0 \%$ & $0 \%$ & $0 \%$ & $0 \%$ \\
\hline
\end{tabular}

Table 2: Correlation between increase of limonin concentration from $15.6 \mu \mathrm{g} / \mathrm{ml}-125 \mu \mathrm{g} / \mathrm{ml}$ and its effect on worms.

\begin{tabular}{lcc}
\hline \hline & & Limonin \\
\cline { 2 - 3 } & Correlation coefficient & $P$ value \\
\hline Dead worm (male) & 0.608 & $0.036^{*}$ \\
Motor activity reduction (male) & 0.626 & $0.029^{*}$ \\
Motor activity reduction (female) & 0.624 & $0.03^{*}$ \\
\hline \hline
\end{tabular}

$*=$ significant $(P<0.05)$

By SEM, prominent changes in adult $S$. mansoni male tegument were observed (Figure 2). The severity and pattern of these morphological alterations depended on the concentration of limonin. This effect progressively intensified with the increase of the limonin concentration and incubation period. Both adult males and females were affected even at lower concentrations where mild to moderate tegumental alterations were observed. Severely damaged worms were observed at higher concentrations as there was massive tegumental destruction exposing the sub-tegumental tissues. Abnormal body attitude, flattened spines, shrinking, corrugations, unfolding and widening of the gynecophoral canal, and sloughing and disintegration of the tegument were observed on the tegument of examined worms. 


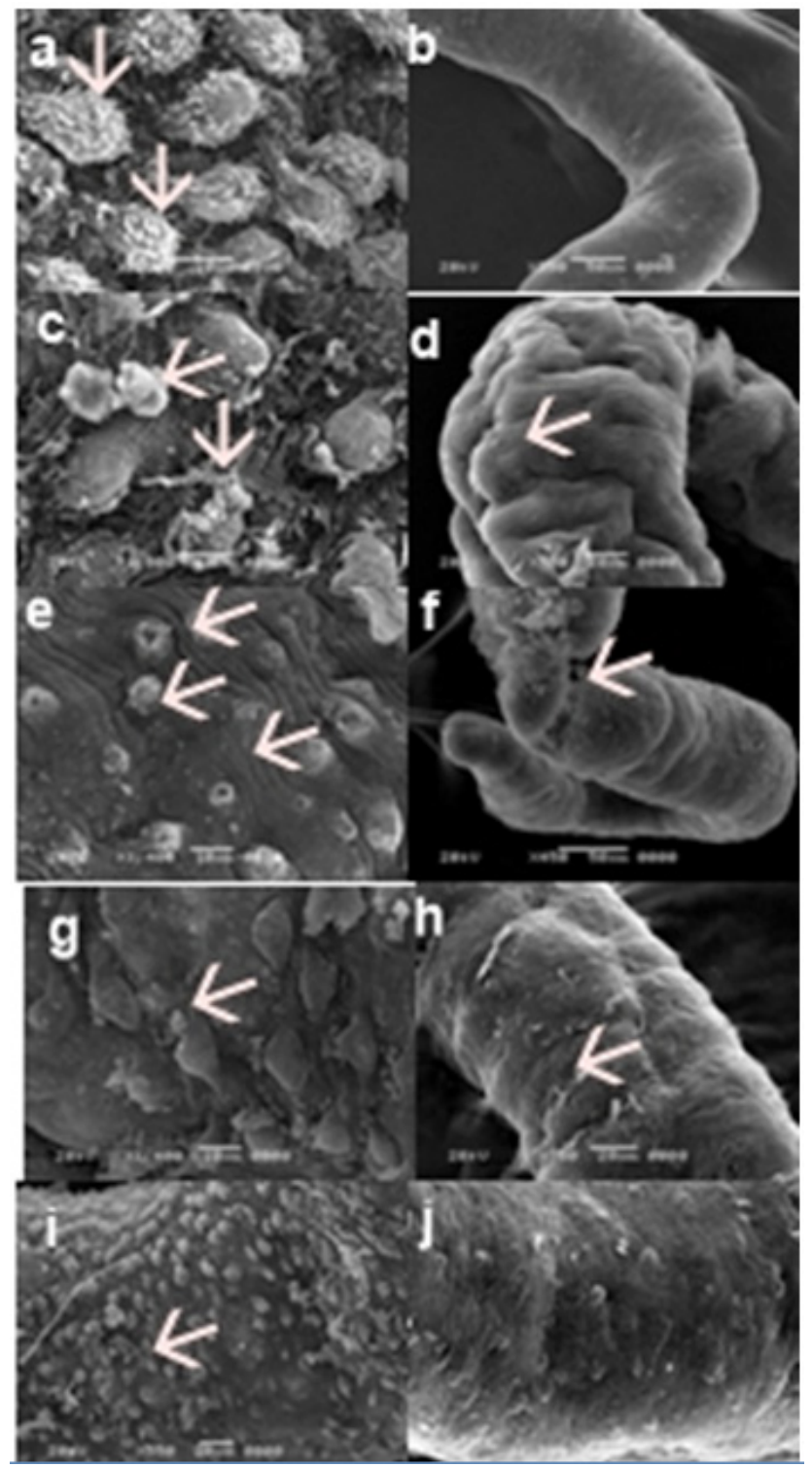

Fig. 2: Scanning electron microscopy of adult $S$. mansoni showing negative control worms with (a) normal tegument for adult male with normal tubercles covered by pointed spines with regular inter-tubercular spaces, (b) normal smooth intact tegument of female worm.

PZQ treated worms showing (c) severely damaged tegument of adult male following exposure to $1.0 \mu \mathrm{g} / \mathrm{ml}$, (d) marked corrugation of female tegument. Exposure to $125.0 \mu \mathrm{g} / \mathrm{ml} \mathrm{limonin}$ in vitro showing (e) destruction of tegument, rupture of tubercles with loss of spines and irregular inter-tubercular spaces in male worm, (f) distortion and destruction of female tegument.

Exposure to $62.5 \mu \mathrm{g} / \mathrm{ml}$ concentration showing (g) male worm reduction in number of tubercles and widening of inter-tubercular spaces, (h) moderate destruction of female tegument with multiple erosions and holes.

Exposure to $31.2 \mu \mathrm{g} / \mathrm{ml}$ limonin (i \& j) showing mild effects on the tegument.

\section{DISCUSSION}

Traditional chemical drugs are not fully effective against schistosomiasis due to the evolving drug resistant worm strains, so exploring new remedies derived from natural products is promising in combating schistosomiasis ${ }^{[36]}$.
Limonin was reported to possess a wide range of biological activities that include antibacterial, anti-malarial, antiviral activities, in addition to its hepatoprotective effects ${ }^{[22]}$ and anticancer efficacy ${ }^{[37]}$. In 2012, the larvicidal activity of citrus limonoids (limonin and nomilin) against Aedes albopictus larvae was reported to be due to anti-feeding and larvicidal activity ${ }^{[38]}$. Oral administration of limonin to $S$. mansoni experimentally infected mice resulted in worm burden reduction and significant reductions in both hepatic and intestinal tissue egg loads with elevated dead egg levels. Limonin also produced reduction in dimensions and number of hepatic granulomas ${ }^{[39]}$. In the present study, we investigated the in vitro schistosomicidal activity of pure limonin compound against adult $S$. mansoni worms. The observations in the negative and positive control groups are similar to previously described studies .

Investigations of the effect of PZQ and other natural compounds such as ginger extract (Zinger officinale) ${ }^{[43]}$, and other natural products such as volatile organic components of Ageratum conyzoides ${ }^{[44]}$ on S. mansoni, reported the greater susceptibility of adult male worms than female worms ${ }^{[43,45]}$. In contrast, artenusate showed higher survival rates of adult male than female worms ${ }^{[46]}$. Tegumental damage may not always result in death of worms ${ }^{[47]}$, but the morphological alterations observed in our study are a result of the mechanism by which limonin kills the parasites. The resulting damage would expose hidden parasite antigens and consequently allow parasite attack by the host immune system. These tegumental alteration are similar to those induced by other drugs as $\mathrm{PZQ}^{[48]}$ and other plant derived compounds ${ }^{[49]}$. No tegumental alterations were observed in the negative controls (RPMI and RPMI with $0.5 \%$ DMSO) until the end of the experiment ( $96 \mathrm{~h}$ ), while the majority of schistosomes exposed to the reference drug (PZQ) showed pronounced tegumental changes similar to reports by previous studies ${ }^{[40-42]}$.

As previously observed, finding a new compound that can kill parasites is not difficult, but the difficulty is to find a substance that can effectively kill the parasite without affecting the host ${ }^{[33]}$. Limonin is not only tolerable and safe but also exerts protective effects on liver toxicity associated with inflammation and tissue injury via attenuation of inflammation and reduction of oxidative stress ${ }^{[22]}$. Thus limonin may be a promising anti-schistosomal replacement therapy.

The exact mechanism by which the pure compound limonin exerts its effect on $S$. mansoni adult worm is still unclear. However, all the dead schistosomes showed massive tegumental affection. In addition, those still alive with affected motility also showed a variable degree of tegumental damage. Thus a relationship between the severity of tegumental damage and worm death was observed in the currently performed in vitro assay using different limonin concentrations. 
In conclusion, we have reported here the in vitro antischistosomicial properties of limonin against adult $S$. mansoni. This study has highlighted $S$. mansoni as a possible new target for limonin therapy. However, further studies are required to confirm its action. Experiments to evaluate limonin in vivo with mice infected by S. mansoni are in progress.

Competing interest: The authors have declared that no competing interests exist.

Authors' contributions: GA Rashed, AA Elkholy conceived, designed, performed the experiments, analyzed the data and revised the manuscript. DI Hemdan contributed reagents/materials (purification of the plant materials). All authors revised and approved the final manuscript.

\section{REFERENCES}

1. WHO . Schistosomiasis: number of people receiving preventive chemotherapy in 2012. Wkly Epidemiol Rec 2014; 89: 21-28.

2. WHO. Schistosomiasis: number of people treated worldwide in 2013. Wkly Epidemiol Rec 2015; 90: 25-32.

3. Assaré RK, Hürlimann E, Ouattara M, N'Guessan N, Tian-Bi Y-N, Yapi A, et al. Sustaining the control of Schistosoma mansoni in western Côte d'Ivoire: baseline findings before the implementation of a randomized trial. Am J Trop Med Hyg 2015; 94(2): 352-360.

4. Assaré RK, Tian-Bi Y-NT, Yao PK, N'Guessan NA, Ouattara M, Yapi A, Coulibaly JT, et al Sustaining control of schistosomiasis mansoni in western Côted'Ivoire: results from a SCORE study, one year after initial praziquantel administration. PLoS Negl Trop Dis 2016; 10(1): e0004329.

5. Speich B, Ali SM, Ame SM, Albonico M, Utzinger J, Keiser J . Quality control in the diagnosis of Trichuris trichiura and Ascaris lumbricoides using the KatoKatz technique: experience from three randomised controlled trials. Parasit Vectors 2015; 8: 82-89.

6. Caffrey CR. Chemotherapy of schistosomiasis: present and future. Curr Opin Chem Biol 2007; 11: 433-439.

7. Molgaard P, Nielsen SB, Rasmussen DE, Drummond RB, Makaza N, Andreassen J. Anthelminthic screening of Zimbabwean plants traditionally used against schistosomiasis. J Ethnopharmacol 2001;74: 257-264.

8. Kayser O, Kiderlen AF, Croft SL. Natural products as antiparasitic drugs. Parasitol Res 2003; 90: 555-562.
9. Parreira NA, Magalhães LG, Morais DR, Caixeta $\mathrm{SC}$, de Sousa JP, Bastos JK, et al. Antiprotozoal, schistosomicidal, and antimicrobial activities of the essential oil from the leaves of Baccharis dracunculifolia. Chem Biodivers 2010; 7: 993-1001.

10. Abaza SM. Treatment of schistosomiasis: From Praziquantel to development of new drug targets. PUJ 2013; 6(2): 127-148

11. Poulose SM, Harris ED, Patil BS. Antiproliferative effects of citrus limonoids against human neuroblastoma and colonic adenocarcinoma cells. Nutr Cancer 2006; 56(1): 103-112.

12. Roy A, Saraf S. Limonoids: overview of significant bioactive triterpenes distributed in plants kingdom. Biolo Pharm Bull 2006; 29: 191-201.

13. Zhang Y, Wang JS, Wang XB, Gu YC, Wei DD, Guo $\mathrm{C}$, et al. Limonoids from the fruits of Aphanamixis polystachya (Meliaceae) and their biological activities. J Agric Food Chem 2013; 61(9): 2171-2182.

14. Kurowska EM, Borradaile NM, Spence JD, Carroll KK. Hypocholesterolemic effects of dietary citrus juices in rabbits. Nutr Res 2000a; 20: 121-129.

15. Kurowska EM, Spence JD, Jordan J, Wetmore S, Freeman DJ, Piche LA, et al. HDL-cholesterolraising effect of orange juice in subjects with hypercholesterolemia. Am J Clin Nut 2000; 72: 10951100.

16. Battinelli L, Mengoni F, Lichtner M, Mazzanti G, Saija A, Mastroianni CM, et al. Effect of limonin and nomilin on HIV-1 replication on infected human mononuclear cells. Planta Med 2003; 69: 910-913.

17. Miller EG, Porter JL, Binnie WH, Guo IY, Hasegawa S. Further studies on the anticancer activity of citrus limonoids. J Agric Food Chem 2004; 52: 4908-4912.

18. Manners GD. Citrus limonoids: Analysis, bioactivity, and biomedical prospects. J Agric Food Chem 2007; 55: 8285-8294.

19. El-Readi MZ, Hamdan D, Farrag N, El-Shazly A, Wink M. Inhibition of P-glycoprotein activity by limonin and other secondary metabolites from Citrus species in human colon and leukaemia cell lines. Eur J Pharmacol 2010; 626(2): 139-145.

20. Bayazit V, Konar V. Biochemical and physiological evaluations of limonoids as potential cancer destroyers. J Anim Vet Adv. 2010; 9(7): 1099-1107. 
21. Rahman A, Siddiqui SA, Jakhar R, Kang SC. Growth inhibition of various human cancer cell lines by imperatorin and limonin from Poncirus trifoliata rafin seeds. Anticancer Agents Med Chem 2015;15(2): 236241.

22. Mahmoud MF, Hamdan DI, Wink M, El-Shazly AM. Hepatoprotective effect of limonin, a natural limonoid from the seed of Citrus aurantium var. bigaradia, on D-galactosamine-induced liver injury in rats. Naunyn Schmiedebergs Arch Pharmacol 2014; 387(3): 251261.

23. Jiraungkoorskul W, Sahaphong S, Sobhon $P$, Riengrojpitak S, Kangwanrangsan N. Effects of praziquantel and artesunate on the tegument of adult Schistosoma mekongi harbored in mice. Parasitol Int 2005; 54(3): 177-183.

24. Mostafa OMS. Effects of sedr honey and/or blackseed oil on Schistosoma mansoni in albino mice: parasitological, biochemical and scanning electron microscopical studies. Egypt J Zool 2005; 45: 449469.

25. de Oliveira RN, Rehder VL, Santos Oliveira AS, Júnior ÍM, de Carvalho JE, de Ruiz AL, et al. Schistosoma mansoni: in vitro schistosomicidal activity of essential oil of Baccharis trimera (less) DC. Exp Parasitol 2002; 132(2): 135-143

26. Hamed MA and Hetta MH. Efficacy of Citrus reticulata and Mirazid in treatment of Schistosoma mansoni. Mem Inst Oswaldo Cruz 2005; 100(7): 771778.

27. El-Lakkany NM, Seif El-Din SH. Haemin enhances the in vivo efficacy of artemether against juvenile and adult Schistosoma mansoni in mice. Parasitol Res 2013; 112: 2005-2015.

28. Hamdan D, El-Readi M, Tahrani A, Herrmann F, Kaufmann D, Farrag N, et al. Chemical composition and biological activity of Citrus jambhiri Lush. Food Chem. 2011; 127: 394-403.

29. Yousif F, Hifnawy MS, Soliman G, Boulos L, Labib L, Mahmoud S, et al. Large-scale in vitro screening of Egyptian native and cultivated plants for schistosomicidal activity. Pharm Biol 2007; 45(6): 501-510.

30. El-Beshbishi SN, El Bardicy S, Tadros M, Ayoub M, Taman A. Spotlight on the in vitro effect of artemisininnaphthoquine phosphate on Schistosoma mansoni and its snail host Biomphalaria alexandrina. Acta Trop 2015; 141(Pt A): 37-45.
31. De Moraes J, de Oliveira RN, Costa JP, Junior ALG, de Sousa DP, Freitas RM, et al. Phytol, a diterpene alcohol from chlorophyll, as a drug against neglected tropical disease schistosomiasis mansoni. PLoS Negl Trop Dis 2014; 8: e2617.

32. Manneck T, Haggenmüller Y, Keiser J. Morphological effects and tegumental alterations induced by mefloquine on schistosomula and adult flukes of Schistosoma mansoni. Parasitol 2010; 137: 85-98.

33. De Moraes J. Antischistosomal natural compounds: present challenges for new drug screens. In: Rodriguez-Morales, A.J. (Ed.), Current Topics in Tropical Medicine. Intech, Rijeka. 2012; pp. 333-358.

34. Hassan MM, El-Motaiem M, Afifi H, Abaza B, ElShafei M, Massoud AM. In vitro effect of mirazid on Schistosoma mansoni worms. J Egypt Soc Parasitol. 2003; 33(3): 999-1008.

35. de Oliveira RN, Rehder VL, Oliveira AS, Jeraldo Vde.L, Linhares AX, Allegretti SM. Antihelmintic activity in vitro and in vivo of Baccharis trimera (Less) DC against immature and adult worms of Schistosoma mansoni. Exp Parasitol. 2014; 139:63-72.

36. Ali M, Eldahab MA, Mansour HA, Nigm A. Schistosoma mansoni: Antiparasitic effects of orally administered Nigella sativa oil and/or Chroococcus turgidus extract. Acta Biol Hung. 2016; 67(3): 247-60.

37. Shimizu S, Miyamoto S, Fujii G, Nakanishi R, Onuma W, Ozaki Y, Mutoh M. Suppression of intestinal carcinogenesis in Apc-mutant mice by limonin. J Clin Biochem Nutr. 2015; 57(1); 39-43.

38. Bilal H, Akram W, Ali-Hassan S. Larvicidal activity of Citrus Limonoids against Aedes albopictus larvae. J Arthropod Borne Dis 2012; 6(2): 104-111.

39. Eraky MA, El-kholy AA, Rashed GA, Hammam OA, Moharam AF, Abou-Ouf EA, et al. Dose-response relationship in Schistosoma mansoni juvenile and adult stages following limonin treatment in experimentally infected mice. Parasitol Res 2016; 115: 4045-4054.

40. De Moraes J, Carvalho AA, Nakano E, de Almeida AA, Marques TH. Anthelmintic activity of carvacryl acetate against Schistosoma mansoni. Parasitol Res 2013; 112: 603-610.

41. Magalhães LG, Kapadia GJ, da Silva Tonuci LR, Caixeta SC, Parreira NA, Rodrigues V, et al. In vitro schistosomicidal effects of some phloroglucinol derivatives from Dryopteris species against Schistosoma mansoni adult worms. Parasitol Res 2010; 106: 395-401 
42. De Souza FF, Júnior COR, Fernandes TS, da Silveira LS, Rezende CAM, de Almeida MV, et al. Anthelmintic effects of alkylated diamines and amino alcohols against Schistosoma mansoni. Biomed Res Int 2013; 783490.

43. Sanderson L, Bartlett A, Whitfield PJ. In vitro and in vivo studies on the bioactivity of a ginger (Zingiber officinale) extract towards adult schistosomes and their egg production. J Helminthol 2002;76: 241-247.

44. De Melo NI, Magalhaes LG, de Carvalho CE, Wakabayashi KA, de P Aguiar G, Ramos RC, et al. Schistosomicidal activity of the essential oil of Ageratum conyzoides L. (Asteraceae) against adult Schistosoma mansoni worms. Molecules 2011; 16: 762-773.

45. Pica-Mattoccia L, Cioli D. Sex- and stage-related sensitivity of Schistosoma. mansoni to in vivo and in vitro Praziquantel treatment. Int J Parasitol 2004; 34: 527-533.
46. Mitsui Y, Miura, M, Aoki Y. In vitro effects of artesunate on the survival of worm pairs and egg production of Schistosoma mansoni. J Helminthol 2009; 83(1): 7-11.

47. Shuhua X, Binggui S, Chollet J, Tanner M. Tegumental changes in adult Schistosoma mansoni harboured in mice treated with Praziquantel enantiomers. Acta Trop 2000;76: 107-117.

48. Fallon PG, Fookes RE, Wharton GA. Temporal differences in Praziquantel- and oxamniquine-induced tegumental damage to adult Schistosoma mansoni: implications for drug-antibody synergy. Parasitol 1996; 112 (1): 47-58.

49. Zhang SM, Coultas KA. Identification of plumbagin and sanguinarine as effective chemotherapeutic agents for treatment of schistosomiasis. Int J Parasitol Drugs Drug Resist 2013; 3: 28-34. 